\title{
INTEGRITAS DAN KEPEMIMPINAN MILENIAL: KASUS PADA HR LEADER
}

\author{
Integrity and Millennial Leadership: Case at HR Leader
}

\author{
Antoni L. Arifin ${ }^{1 *}$ \\ M. Takrim ${ }^{2}$ \\ *IInstitut Ilmu Sosial Dan \\ Manajemen STIAMI, Jakarta, \\ DKI Jakarta, Indonesia \\ 2 Universitas Bina Insani, Bekasi, \\ Jawa Barat, Indonesia \\ *email: ludfi@stiami.ac.id
}

\section{Kata Kunci: \\ Integritas \\ Kepemimpinan \\ Milenial}

\section{Keywords: \\ Integrity \\ Leadership \\ Millennial}

Accepted

Juli 2021

\section{Published}

Agustus 2021

\begin{abstract}
Abstrak
Generasi milenial merupakan generasi yang tumbuh di tengah berkembangnya teknologi dengan pesat. Generasi ini diharapkan sebagai penerus generasi sebelumnya untuk menjadi pemimpin di masa depan. Tujuan dari penelitian ini adalah untuk melihat nilai-nilai integritas pada pemimpin milenial sehingga mampu memberikan pengaruh yang kuat terhadap bawahannya dalam memajukan organisasi. Penelitian ini adalah penelitian kuantitatif deskriptif dengan melakukan survei terhadap HR Leader. Data diperoleh dari para milenial pada rentang usia 20-40 tahun dengan posisi minimal supervisor di unit kerja/divisi/departemen SDM sebanyak 107 responden. Data kemudian dianalisis dan diinterpretasikan sehingga menjadi dasar dan rekomendasi kepemimpinan milenial. Dari penelitain ini didapati bahwa integritas, dengan nilai kejujuran, amanah, komitmen, dan kesetiaan telah dijalankan dengan baik. Nilai integritas tersebut merupakan modal penting yang harus dimiliki oleh seorang individu yang akan menjadi pemimpin khususnya pada generasi milenial.
\end{abstract}

\begin{abstract}
Millennial generation is a generation that grows in the midst of rapidly developing technology. This generation is expected to be the successor of the previous generation to become leaders in the future. The purpose of this study is to see the values of integrity in millennial leaders, so they have a strong influence on their subordinates in advancing the organization. This research is a descriptive quantitative study by conducting a survey of $H R$ leaders. Data obtained from millennials in the age range of 20-40 years with a minimum supervisor position in the work unit/division/HR department as many as 107 respondents. The data is analyzed and interpreted so that it becomes the basis and recommendations for millennial leadership. From this research, it was found that integrity, with the values of honesty, trustworthiness, commitment, and loyalty have been carried out well. The value of integrity is an important asset that must be owned by an individual who will become a leader, especially in the millennial generation.
\end{abstract}

(C) 202I The Authors. Published by Institute for Research and Community Services Universitas Muhammadiyah Palangkaraya. This is Open Access article under the CC-BY-SA License (http://creativecommons.org/licenses/by-sa/4.0/).

\section{PENDAHULUAN}

Generasi milenial saat ini sedang menjadi pembahasan pada hampir setiap bidang keilmuan. Mereka saat ini telah masuk dunia kerja dengan posisi yang stategis, di antaranya adalah posisi pemimpin di unit kerja/divisi/departemen sumber daya manusia (SDM), HR leader. Sebagai pemimpin, generasi milenial harus menjadi contoh teladan bagi bawah, teman sejawat, bahkan atasannya. Para pemimpin milenial ini, merupakan aset dan potensi bangsa agar kopetitif menghadapi persaingan.

Generasi Milenial merupakan mereka yang terlahir di antara tahun 1980-2000, di mana era tersebut terjadi perkembangan teknologi yang pesat, dan secara kelompok umur merupakan generasi yang saat ini di antara usia 15-34 tahun (Hidayatullah et al., 2018).

Di masa kelahiran generasi milenial ini, perkembang ilmu pengetahuan dan teknologi begitu pesat, serta masuknya pengaruh budaya dari luar yang mempengaruhi gaya hidup serta kepribadian generasi tersebut. Karenanya. Diharapkan para milenial ini, menjadi penerus generasi sebelumnya. (Achmad et al., 2020) generasi milenial yang berusia 18-40 tahun, memiliki kebiasaan dan mempunyai ingkat antusiasme tinggi terhadap penggunaan teknologi.

Saat ini kita dapat menemukan adanya kehilangan rasa tanggung jawab dari generasi milenial dengan tergerusnya moralitas. Hal ini dinyatakan Presiden RI ke-7, Joko Widodo, 
bahwa bangsa Indoenesia harus melakukan revolusi mental agar menuju bangsa yang besar, akan tetapi apabila tidak dimulai dari pondasinya yaitu generasi muda (milenial), maka semuaanya hanyalah akan menjadi wacana saja. Rukiyanto dalam (Lalo, 2018) pendidikan intelektual tidak cukup diberikan kepada seseorang, tetapi mereka juga harus diberi bekal pendidikan moral dan spiritualnya.

Pendidikan moral bertujuan mengubah perilaku sejak dini pada anak, sehingga jika mereka dewasa nanti akan lebih menghargai sesame, bertanggun jawab, dan mampu menghadapi tantangan zaman yang cepat berubah. (Sinulingga, 2016). Hal pertama yang dapat kita lakukan untuk merubah moral generasi milenial menjadi lebih baik bisa diawali dengan membangun karakter dari lingkungan terkecil yaitu keluarga, pergaulan, kemudian sekolah untuk menanamkan sifat tanggung jawab dan kepemimpinan sehingga menjadi kader yang mampu membawa organisasi khususnya dan bangsa ini pada umumnya menuju masa depan yang lebih baik. Generasi milenial ini merupakan tonggak masa depan bangsa. Pertaruhan keberhasilan bangsa ini berada di tangan generasi milenial.

Menurut, (Wahono, 2018) seluruh aktivitas belajar dan mengajar di negara Indonesia harus bertolak dan mengarah pada pendidikan karakter anak bangsa. Lebih lanjut menurutnya, nilai karakter integritas adalah nilai yang dijadikan dasar untuk menjadikannya orang yang dapat dipercaya baik ucapan, perbuatan, dan Tindakan.

Integritas pada diri seseorang berkaitan dengan sikap untuk selalu mengutamakan tanggung jawab, kesetiaan terhadap janji, dan kepercayaan. Integritas terkait dengan kemampuan untuk mengendalikan dan menahan diri dari bermacam godaan yang dapt merusak martabat dan harkat mulia seseorang. Seseorang yang memiliki integiritas merupakan orang yang dapat dipercaya, diandalkan, dan dapat diteladani (Gea, 20I4).

Ashford \& Halfon di dalam (Widyarini et al., 2019) menyatakan bahwa seseorang yang memiliki integritas, kewajiban moralnya tinggi dan cenderung selalu benar dalam moral, serta dalam hal lain apabila seseorang menekankan tujuan moral didalam dirinya akan mendorong seseorang tersebut tetap konsisten, mempunyai pemikiran yang logis dan jelas serta berhati-hati didalam mempertimbangkan isu-isu yang berkaitan dengan moral.
Integritas juga dapat diartikan sebagai sebuah kesesuaian antara tindakan dengan prinsip dan nilai yang dipegang teguh, tanpa adanya kepalsuan dan sesuatu yang ditutup-tutupi. Di manapun berada dan dengan kondisi apapun, mereka yang memilliki integritas, tetap memegang prinsip yang dianutnya.

Seseorang yang memiliki integritas yang kuat maka dia dapat mempengaruhi orang lain di sekitar dengan prinsipnya, sehingga dapat mencontohkan perilaku baik dalam kehidupan, bahkan menjadi model bagi generasi penerusnya. Werren Bennis berpendapat: "Di dalam arena kepemimpinan, karakter mempunyai arti”. Seseorang tidak akan jatuh dari kedudukannya (sebagai pemimpin) karena orang tersebut tidak berkompeten secara teknis. Namun banyak sekali orang jatuh, karena perilaku tidak jujur (tidak berintegritas) dan memiliki karakter kurang baik (Wijaya, 2015). Dengan demikian integritas merupakan sifat jujur, karakter atau perilaku baik yang dimiliki seseorang.

Seseorang yang memiliki integritas dapat terlihat dan tergambar dari perilaku orang tersebut. Perilaku yang mencirikan integritas yang baik berupa: a) perilaku jujur; b) sejalan dan konsisten antara apay yang diucapan dengan tindakan; c) mematuhi dan menjalankan aturan dan etika dalam berorganisasi; d) dapat memegang teguh komitmen serta prinsip yang diyakini kebenarannya; e) bertanggung jawab penuh terhadap keputusan, Tindakan dan konsekuensi yang mengikutinya; f) memiliki kualitas diri agar dapat dihormati orang lain; g) konsisten untuk patuh pada etika dan moral yang berlaku di masyarakat; h) memiliki kearifan dalam membedakan mana yang benar dan yang salah, serta dapat mendorong orang lain untuk nenerapkan hal tersebut (Redjeki \& Herdiansyah, 2013).

Para pemimpin di unit kerja/divisi/departemen SDM (HR Leader) berperan penting untuk menarik, mempertahankan, mengembangakan SDM di perusahaan masing-masing. Karenanya integritas di tingkat mereka sangat diharapkan. Integritas yang dibutuhkan pada level kepemimpinan milenial ini adalah kejujuran, amanah, komitmen, dan kesetiaan. Para HR leader adalah mereka yang bekerja di unit kerja/divisi/depatemen SDM, mulai dari fungsi perencanaan SDM, rekrutmen dan seleksi, pelatihan dan pengembangan, kompensasi dan benefit, manajemen talenta, manajemen kinerja, hingga hubungan industrial. 
Kejujuran dibutuhkan untuk menciptakan integritas (Wisesa, 2002). Modal dasar seorang pemimpin adalah berperilaku jujur, karena tanpa kejujuran maka apa yang dilakukan akan sia-sia belaka, seperti apa yang disampaikan (Keselman, 2012), bahawa pemimpin bertintegritas menunjukkan kejujuran pada diri sendiri dan orang lain.

Jujur adalah modal mendasar bagi seorang pemimpin. lebih lanjut Brown \& Trevino (2006) dalam (Yustina, 2017) mengemukakan bahwa pemimpin etis memiliki karakteristik seperti peduli, jujur, dan berpikiran tinggi yang membuat keputusan yang adil. Pada generasi milenial, mereka ini adalah tulang punggung kepemimpinan nasional, karennya perilaku jujur merupakan modal dasar kepemimpinan mereka dalam menggerakan sumber daya, terutama SDM agar mampu menjadi SDM unggul.

Amanah adalah titipan. Kepemimpinan adalah sebuah amanah atau kepercayaan. Kepercayaan yang telah diberikan tidak boleh dikhianati dari yang memberikan kepercayaan tersebut (Amirin, 2007). Amanah merupakan fondasi dasar dalam relasi sosial manusia (Agung \& Husni, 2017).

Seseorang yang mendapatkan amanah jabatan, maka harus dijaga dengan baik kebermanfaatannya bagi perusahaan yang menitipkannya. Menurut (Hapsari \& Masud, 2018), sesorang yang diberikan amanah, maka ia tidak boleh berkhianat terhadap tanggung jawab yang diberikan.

Komitmen kepemimpinan merupakan hal penting untuk meneguhkan pemimpin dan orang yang dipimpin dalam suatu organisasi dapat menjalankan tanggung jawab kepemimpinan yang diembannya (Kasidi, 20I6). Sebagai HR Leader, komitmen untuk menjalankan, memngembangkan, dan memenuhi tanggung jawab tugas-tugas sebagai pemimpin harus dijalankan dengan baik.

Perusahaan menghadapi rendahnya tingkat work engagement karyawan generasi milenial di berbagai belahan dunia (Mulyati et al., 2019). Saat ini, generasi milenial menjadi topik pembicaraan terkait kesetiaan mereka di dunia kerja. (Jha et al., 2019) menyatakan perlunya upaya besar agar meningkatkan keterlibatan milenial dan menjadi salah satu perkerjaan menantang bagi praktisi SDM untuk meningkatakn keterlibatan generasi milenial ini.
Seorang pemimpin yang mempunyai integritas yang kuat, maka mampu memberikan pengaruh yang sangat besar terhadap bawahan yang dipimpinnya untuk memberikan kontribusi yang potisif terhadap kemajuan organisasi. Kepemimpinan artikan sebagai kemampuan seseorang untuk meyakinkan dan mempengaruhi suatu kelompok dalam mencapai tujuan organisasi. Kepemimpinan adalah kemampuan memengaruhi suatu kelompok menuju tercapainya visi atau tujuan yang ditetapkan (Robbins dan Judge, 2015).

\section{Integritas pada Kepemimpinan Millennial}

Hal penting dari gaya kepemimpinan adalah mampu memahami kebutuhan dan harapan khusus dari setiap anggota organisasi. Harapan dan kebutuhan setiap anggota adalah untuk memenuhi pencapaian sasaran dan tujuan organisasi, bukan keinginan dan harapan yang bersifat individu. Tujuan tersebut merupakan tujuan Bersama dalam organisasi, maka seorang pemimpin harus dapat membantu mencapai dan memenuhinya (Sultraini et al., 2019). Kepemimpinan yang ditopang atas dasar kekuatan berpikir dan tindakan yang produktif, yang kemudian berlandaskan kekuatan moral, akan menjadikan seorang pemimpin berintegritas; pemimpin tersebut berperilaku dan bersikap baik, sehingga mampu memberikan mampu mempengaruhi orang lain untuk melakukan dan memberikan keteladanan (Wahyudin, 2016).

Kepemimpinan millennial diartikan sebagai kepemimpinan kekinian yang dapat menyesuaikan gaya generasi yang lahir pada era tahun 1980-an, di mana generasi milenial ini memiliki peran penting. Generasi milenial saat ini memasuki masa paling produktif. Mereka berada pada usia 20-40 tahunan dan mereka mempengaruhi dunia kerja lokal, regional, dan global dari sisi kreativtas dan inovasi.

Ciri generasi milenial ini adalah I) mereka memiliki kemampuan mengakses teknologi informasi secara lebih baik dari generasi sebelumnya, 2) lebih berinovatif dan memiliki keberanian dalam trobosan baru, 3) lebih menyukai kemandirian dan independensi, 4) lebih menyukai sesuatu yang instan (Peramesti \& Kusmana, 2018).

Berbicara mengenai integritas juga tidak lepas dari istilah integritas diri yaitu sebuah integritas yang membahas mengenai kehidupan pribadi seorang pemimpin, bagaimana seorang pribadi tersebut memandang dirinya, bagaimana 
seorang pemimpin melihat kedalam dirinya dan menilai kematangan pribadi dan keberadaan atau kematangan individu secara objektif (Arisma et al., 2019).

Berdasarkan kajian di atas dapat diambil kesimpulan bahwa untuk menjadi seorang pemimpin yang berintegritas, khususnya pemimpin milenial harus dapat mengenal identitas diri dengan benar, karena dengan begitu mereka dapat memberikan pengaruh yang kuat kepada bawahannya; sehingga dapat membawa perubahan ke arah yang lebih baik pada organisasi sesuai dengan tujuan yang diinginkan. Pemimpin yang integritasnya rendah memiliki pengaruh yang kecil pula terhadap orang lain. Seseorang bisa jadi jabatannya tinggi, akan tetapi pengaruhnya kecil atau sedikit. Organisasi tentunya menginginkan seseorang yang memiliki jabatannya tinggi, integritasnya tinggi serta mempunyai pengaruh yang tinggi pula terhadap bawahan atau karyawan lain. integritas diri dapat dilatih dengan membiasakan membuat janji untuk diri sendiri dan berusaha menepati janji tersebut. Apabila sudah terbiasa memenuhi janji pada diri sendiri, kemudian bisa untuk dimulai membuat janji dengan orang lain dan tentunya janji tersebut juga harus ditepati. Penelitian ini bertujuan untuk melihat integritas dan kepemimpinan milenial, terkait dengan kejujuran, amanah, konsisten, dan kesetiaan pada posisi Human Resource (HR) Leader.

\section{METODOLOGI}

Penelitian ini adalah penelitian kuantitatif deskriptif. Data diperoleh dari para milenial dengan usia 20-40 tahun. Data diambil dari komunitas SDM, yaitu SDM Cendekia, Gen HR, Gerakan Nasional Indonesia Kompeten (GNIK), HRBP, Sahabat Kompetensi Indonesa (SKI), dan komunitas SDM lainnya di mana responden tersebar di seluruh wilayah Indonesia. Sugiyono (2012) menyatakan metode deskriptif berjujuan untuk memberi gambaran terhadap sempel, dan membuat analisis dan kesimpulan yang berlaku umum. Di samping itu, Arikunto (2010) menyatakan bahwa dalam penelitian deskriptif, peneliti tidak

bermaksud untuk menguji hipotesis, melaikan bertujuan menggambarkan suatu variable secara apa adanya. Penelitain ini menganalisis setiap variable integritas dan kemudian data dianalisisi dan dikaitkan dengan literatur yang terkait. Sample diambil berdasarkan Formula Lemeshow (1990), dengan formula sebagai berikut:

$$
\mathrm{n}=\frac{Z a^{2} \times P \times Q}{L^{2}}
$$

Keterangan:

$\mathrm{n}$ : Jumlah sampel

Za : Nilai standar dari distribusi sesuai nilai $\alpha=5 \%=1,96$

$\mathrm{P}$ : Prevalensi outcome, karena data belum didapat, maka dipakai $50 \%$

$\mathrm{Q}: \mathrm{I}-\mathrm{P}$

$\mathrm{L}$ : Tingkat ketelitian $10 \%$

Berdasarkan rumus di atas, maka akan dapat ditentukan besarnya sampel sebagai berikut:

$\mathrm{n}=\frac{(1,96)^{2} \times 0,5 \times 0,5}{(0,1)^{2}}=\frac{0,9604}{0,01}=96,04=96$

Jadi, berdasarkan perhitungan di atas ukuran sampel yang digunakan minimal 96 orang. Dari kuesioner yang disebarkan, data yang masuk sebanyak 146 orang, setelah dilakukan kesuaian kriteria responden pada jabatan HR Leader, maka responden yang kami ambil sebesar 107 responden.

\section{HASIL DAN PEMBAHASAN}

Dari 120 responden yang mengisi kuesioner diambil sebanyak 107 yang memenuhi kriteria memiliki jabatan HR Leader.

Tabel I. Profil dan Karakteristik Responden

\begin{tabular}{lr|cccc}
\multicolumn{2}{l}{ Jenis Kelamin } & \multicolumn{5}{c}{ Usia } \\
\hline $\mathrm{L}$ & $\mathrm{P}$ & $21-25$ & $26-30$ & $36-40$ & $36-40$ \\
& & & & & \\
\hline 60 & 47 & 4 & 22 & 37 & 44 \\
& & & & & \\
\hline $56.07 \%$ & $43.93 \%$ & $3.74 \%$ & $20.56 \%$ & $34.58 \%$ & $41.12 \%$
\end{tabular}

Berdasarkan profil dan karakteristik 107 responden $H R$ Leader, di dapat responden berjenis kelamin laki-laki yaitu sebanyak $56,07 \%$ dan perempuan sebanyak 43,93\%, usia mereka adalah usia produktif dengan jumlah paling banyak di rentang 36-40 tahun, yaitu sebanyak $41,12 \%$, dengan jumlah paling kecil di usia $21-25$ tahun sebesar $3,74 \%$. 
Tabel 2. Lama Bekerja di Bidang SDM

Lama Bekerja di Bidang SDM

\begin{tabular}{cccc}
\hline$\leq 5$ tahun & $6-10$ tahun & $\mathrm{II}-\mathrm{I} 5$ tahun & $\geq 16$ tahun \\
\hline 27 & 46 & 24 & 10 \\
\hline $25.23 \%$ & $42.99 \%$ & $22.43 \%$ & $9.35 \%$ \\
\hline
\end{tabular}

Responden paling lama bekerja di bidang SDM, yaitu 6-10 tahun sebesar 42,99\%, kurang dari 5 tahun sebesar 25,23\%, disusul 22,43\% telah bekerja II-I5 tahun, dan sisanya $9,35 \%$ telah bekerja di atas 16 tahun.

\section{Tabel 3. Tingkat Kejujuran}

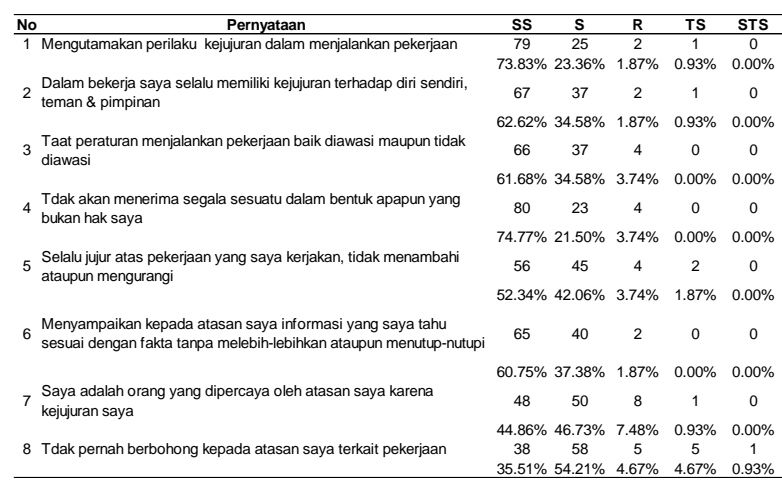

Kejujuran merupakan hal penting. Kejujuran berarti menyampaikan kebenaran, ucapan sesuai dengan kenyataan (Muhasim, 2017). Tanpa nilai kejujuran, dan anggota organisasi hanya mengedepankan kepura-puraan, kebohongan, dusta, dan nilai ketidakjujuran lainnya, hanya akan menyebabkan organisasi mengalami keracunan/toksik budaya. Sumani dalam (lqbal \& Prawening, 2018) jujur merupakan perilaku yang menyatakan sesuatu itu apa adanya, terbuka, konsisten antara perkataan dan perilaku, serta tidak melakukan tindakan curang.

HR Leader, dalam menjalankan aktivitas keseharian di perusahaan juga harus menekankan perilaku jujur. Kejujuran ini diimplementasikan dalam aktivitas keseharian mulai dari aktivitas rekrutmen, seleksi, pelatihan, kompensasi dan benefit, hingga aktivitas hubungan industrial. Berdasarkan tabel tingkat kejujuran di atas, temuan data menunjukkan mayoritas

HR Leader sangat setuju bahwa HR Leader harus mengutamakan perilaku jujur dalam menjalankan pekerjaan sebesar $73,83 \%$. Sangat setuju untuk memiliki kejujuran terhadap diri sendiri, teman, dan pimpinan sebesar $62,62 \%$. Sangat setuju untuk taat pada peraturan saat diawasi maupun tanpa pengawasan sebesar $61,68 \%$. Sangat setuju untuk tidak akan menerima sesuatu dalam bentuk apapun sebesar $74,77 \%$. Sangat setuju untuk selalu jujur atas pekerjaan tampa menambahi atau mengurangi sebesar $52,34 \%$. Sangat setuju untuk menyampaikan informasi kepada atasan tanpa melebihlebihkan atau menutup-nutupi sebesar $60,75 \%$. Setuju bahwa $H R$ leader adalah orang yang dapat dipercaya karena kejujuran, sebesar $46,73 \%$. Setuju untuk tidak pernah berbohong kepada atasan sebesar $54,21 \%$.

Menginternalisasikan dan menanamkan nilai-nilai kejujuran, di dunia korporasi menjadi semakin penting. Namun, hal ini menjadi sulit ketika kurangnya keteladanan dari para pemimpin. Upaya HR leader untuk menjadi contoh (role model) adalah penting, begitu pun diri kita sendiri, menentukan perilaku kejujuran di tempat kerja. Hal ini sesuai apa yang disampaikan (Dwi, 2017) bahwa menjadi karyawan yang memiliki kepribadian moral, merupayakan upaya yang harus dilakukan oleh pekerja sehingga dapat terus menjadikan dirinya sebagai pribadi yang bermanfaat.

Perilaku jujur, saat ini merupakan perbuatan langka, nilai-nilai kejujuran harus terus diciptakan dengan proses pembentukan kembali nilai-nilai karakter (Aisyah, 2019). Pada HR Leader, Perilaku jujur ini menjadi penting karena SDM adalah fungsi yang mendukung unit kerja lainnya. Menurut (Maulana et al., 2018) seluruh karyawan harus memiliki sikap jujur. Kejujuran adalah akhlak mulia yang harus dimiliki, baik jujur dalam berbicara, jujur dalam sikap, jujur dalam berinteraksi sosial. Modal kejujuran karayawan ini dapat mempengaruhi proses bisnis perusahaan.

Tabel 4. Tingkat Amanah

\begin{tabular}{|c|c|c|c|c|c|}
\hline & lo $\quad$ Pernyataan & SS & $\mathbf{R}$ & TS & STS \\
\hline \multirow{2}{*}{$1 \mathrm{~T}$} & Merasakan bahwa pekerjaan yang saya lakukan adalah titipan dari & 27 & 0 & 1 & 0 \\
\hline & & $73.83 \% 25.23 \%$ & $0.00 \%$ & $0.93 \%$ & $0.00 \%$ \\
\hline & Menyelesaikan tugas sendiri dengan tidak dilimpahkan kepada orang & 50 & 6 & 12 & 1 \\
\hline & & $35.51 \% 46.73 \%$ & $5.61 \%$ & $11.21 \%$ & $0.93 \%$ \\
\hline \multirow{2}{*}{\multicolumn{2}{|c|}{$\begin{array}{l}3 \text { Mampu menyelesaikan pekerjaan tepat waktu atau lebih cepat dari } \\
\text { yang ditargetkan }\end{array}$}} & 61 & 12 & 1 & 1 \\
\hline & & $29.91 \% 57.01 \%$ & $11.21 \%$ & $0.93 \%$ & $0.93 \%$ \\
\hline \multirow{2}{*}{\multicolumn{2}{|c|}{$\begin{array}{l}4 \text { Tidak pernah mengeluh dengan pekerjaan yang diberikan oleh } \\
\text { atasan kepada saya }\end{array}$}} & 42 & 23 & 9 & 0 \\
\hline & & $30.84 \% 39.25 \%$ & $21.50 \%$ & $8.41 \%$ & $0.00 \%$ \\
\hline \multirow{2}{*}{\multicolumn{2}{|c|}{$5 \begin{array}{l}\text { Say } \\
\text { ata }\end{array}$}} & 52 & 6 & 1 & 0 \\
\hline & & $44.86 \% 48.60 \%$ & $5.61 \%$ & $0.93 \%$ & $0.00 \%$ \\
\hline \multirow{2}{*}{\multicolumn{2}{|c|}{$\begin{array}{l}\text { Tidak pernah mengecewakan atasan saya atas amanah yang } \\
\text { dibebankan kepada saya }\end{array}$}} & $31 \quad 55$ & 17 & 4 & 0 \\
\hline & & $28.97 \% 51.40 \%$ & $15.89 \%$ & $3.74 \%$ & $0.00 \%$ \\
\hline \multirow{2}{*}{\multicolumn{2}{|c|}{$\begin{array}{l}7 \begin{array}{l}\text { Saya menerima amanah dari atasan, saya akan segera } \\
\text { melaksanakannya tanpa menunda-nunda }\end{array} \\
\text {. }\end{array}$}} & $36 \quad 62$ & 8 & 1 & 0 \\
\hline & & $33.64 \% 57.94 \%$ & $7.48 \%$ & $0.93 \%$ & $0.00 \%$ \\
\hline \multicolumn{2}{|r|}{$\begin{array}{l}8 \text { Tidak pernah lupa/lalai dengan amanah yang dibebankan kepada } \\
\text { saya }\end{array}$} & $27 \quad 62$ & 14 & 4 & 0 \\
\hline
\end{tabular}


Penelitian (Hadiansyah \& Yanwar, 2017) menunjukan bahwa kerja adalah amanah. Amanah adalah aspek yang paling berperan dalam mempengaruhi kinerja karyawan. Dalam penelitiannya didapati bahwa kinerja karyawan dipengaruhi secara positif dan signifikan oleh aspek kerja adalah amanah, dan sebaliknya apabila karywan beranggapan bahwa kerja bukanlah amanah, maka akan menyebabkan penurunan kinerja karyawan.

Berdasarkan tabel Amanah di atas, didapati bahwa HR Leader sangat setuju merasakan bahwa pekerjaan yang saya lakukan adalah titipan dari Tuhan sebenyak $73,83 \%$, setuju bahwa $H R$ Leader dapat menyelesaikan tugas saya sendiri tidak dilimpahkan kepada orang lain sebesar $46,73 \%$, setuju mampu menyelesaikan pekerjaan saya tepat waktu atau lebih cepat dari yang ditargetkan $57,01 \%$, setuju untuk tidak pernah mengeluh dengan pekerjaan yang diberikan diberikan $39,25 \%$; setuju bahwa saya adalah orang yang dipercaya untuk menjaga atau menyampaikan amanah $48,60 \%$; setuju bahwa tidak pernah mengecewakan atasan saya dengan amanah yang dibebankan 5I,40\%; setuju bahwa menerima amanah dari atasan, saya akan segera melaksanakannya tanpa menundanunda 57,94\%; dan setuju bahwa ia tidak pernah lupa/lalai dengan amanah yang dibebankan kepadanya $57,94 \%$.

Dari data HR Leader tersebut, tampak bahwa para pemimpin di dunia SDM menganggap bahwa amanah adalah titipan yang harus diterima, dijalankan, dan dijaga dengan baik. Terbukti bahwa nilai-nilai keamanahan ini masih dijalankan dengan baik. Menurut (Noviandani \& Septiarini, 2017) amanah berarti memiliki tanggung jawab dalam menjalankan setiap kewajiban dan tugas yang diberikan. Amanah diwujudkan dalam kejujuran, keterbukaan, dan pelayanan yang optimal, dan perbuat yang baik dalam segala hal.

Tabel 5. Tingkat Komitmen

\begin{tabular}{|c|c|c|c|c|c|c|}
\hline \multirow{3}{*}{\multicolumn{2}{|c|}{$\begin{array}{l}\text { Kerja efektif merupakan komitmen dalam menjalankan setiap } \\
\text { aktivitas kerja }\end{array}$}} & ss & $\mathbf{s}$ & $\mathbf{R}$ & TS & STS \\
\hline & & 60 & 45 & 2 & 0 & 0 \\
\hline & & $56.07 \%$ & $42.06 \%$ & $1.87 \%$ & $0.00 \%$ & $0.00 \%$ \\
\hline \multirow{2}{*}{\multicolumn{2}{|c|}{$\begin{array}{l}2 \text { Saya merasa masalah yang terjadi di perusahaan menjadi } \\
\text { permasalahan saya juga }\end{array}$}} & 31 & 50 & 15 & 11 & 0 \\
\hline & & $28.97 \%$ & $46.73 \%$ & $14.02 \%$ & $10.28 \%$ & $0.00 \%$ \\
\hline \multicolumn{2}{|r|}{3 Selalu bersemangat dalam menjalankan pekerjaan saya } & $\begin{aligned} 43 \\
40.19 \%\end{aligned}$ & $\begin{aligned} 58 \\
54.21 \%\end{aligned}$ & $\begin{aligned} 6 \\
5.61 \% \\
\end{aligned}$ & $\begin{array}{c}0 \\
0.00 \% \\
\end{array}$ & $\begin{array}{c}0 \\
0.00 \% \\
\end{array}$ \\
\hline & $\begin{array}{l}\text { Selalu memotivasi diri saya sendiri dan teman saya untuk } \\
\text { menyelesaikan pekerjaan }\end{array}$ & 53 & 53 & 1 & 0 & 0 \\
\hline & & $49.53 \%$ & $49.53 \%$ & $0.93 \%$ & $0.00 \%$ & $0.00 \%$ \\
\hline & $\begin{array}{l}\text { Merasa benar-benar menjadi salah satu bagian dari perusahaan, } \\
\text { bukan orang lain }\end{array}$ & 49 & 52 & 4 & 2 & 0 \\
\hline & & $45.79 \%$ & $48.60 \%$ & $3.74 \%$ & $1.87 \%$ & $0.00 \%$ \\
\hline & Memiliki komitmen yang tinggi terhadap perusahaan & $\begin{array}{r}49 \\
4579 \%\end{array}$ & $\begin{aligned} 50 \\
4673 \%\end{aligned}$ & $\begin{array}{c}7 \\
654 \%\end{array}$ & $\begin{aligned} 1 \\
093 \%\end{aligned}$ & $\begin{array}{rll}0 \\
0.00 \%\end{array}$ \\
\hline & $\begin{array}{l}\text { Merasa terikat secara emosional dengan perusahaan tempat saya } \\
\text { bekerja }\end{array}$ & 39 & 54 & 11 & 3 & 0 \\
\hline & & $36.45 \%$ & $50.47 \%$ & $10.28 \%$ & $2.80 \%$ & $0.00 \%$ \\
\hline \multirow[t]{2}{*}{$8 \stackrel{3}{s}$} & $\begin{array}{l}\text { Sulit terikat dengan perusahaan lain seperti perusahaan di tempat } \\
\text { saya bekerja }\end{array}$ & 21 & 33 & 39 & 13 & 1 \\
\hline & & $19.63 \%$ & $30.84 \%$ & $36.45 \%$ & $12.15 \%$ & $0.93 \%$ \\
\hline
\end{tabular}

Komitmen adalah suatu sikap yang wajib dimiliki karyawan. Komitmen ini memperlihatkan loyalitas karyawan terhadap organisasi tempat mereka bekerja. Komitmen organisasi terkait erat dengan aspek psikologis dalam menerima dan memercayai nilai dan arah tujuan organisasi. Komitmen ini muncul berupa keinginan karyawan untuk tetap mempertahankan keanggotaannya dalam organisasi (Halimsetiono, 20/4).

Perusahaan memerlukan pemimpin yang mampu membawa organisasi untuk tetap menjaga konsistensi dan tahan bersaing di dunia bisnis. Peran kepemimpinan sangat penting bagi perusahaan atau organisasi dalam pencapaian visi, misi, dan tujuan perusahaan. Jika tidak ada seorang pemimpin dalam organisasi, maka dapat menyebabkan perusahaan tersebut mengalami kemunduran (Darmawan \& Putri, 2016). Lebih lanjut (Zahra, 20I5) menekankan bahwa komitmen karyawan terhadap organisasi sangat diperlukan dan mejadi kekuatan penting untuk dapat bersaing.

Berdasarkan tabel komitmen di atas, didapati bahwa HR Leader sangat setuju bahwa kerja efektif merupakan komitmen dalam menjalankan setiap aktivitas kerja sebesar $56,07 \%$; setuju bahwa masalah yang terjadi di perusahaan menjadi permasalahan HR Leader sebesara 46,73\%; setuju bahwa harus bersemangat dalam menjalankan pekerjaan sebesar $54,21 \%$; sangat setuju selalu bersemangat memotivasi diri saya sendiri dan teman saya untuk menyelesaikan pekerjaan 49,53\%; setuju merasa benar-benar menjadi salah satu bagian dari perusahaan, bukan orang lain sebesar $48,60 \%$; setuju bahwa HR Leader harus memiliki komitmen yang tinggi terhadap perusahaan $46,73 \%$; setuju bahwa selalu merasa terikat secara emosional dengan perusahaan tempat saya bekerja 50,47\%; dan ragu untuk terikat dengan perusahaan lain seperti perusahaan di tempat saya bekerja $36,45 \%$. Kami mendapati, hasil survei, bahwa komitmen HR Leader untuk berkontribusi pada organisasi cukup tinggi.

Komitmen HR Leader untuk bekerja dan menjalankan berbagai fungsi pendukung (supporting function) bagi perusahaan dan unit kerja lain menjadi lebih baik. Menurut (Gilbert et al., 2010) menyatakan kualitas layanan yang tinggi oleh departemen SDM memiliki efek positif tambahan pada komitmen afektif karyawan. 


\section{Tabel 6. Tingkat Kesetiaan}

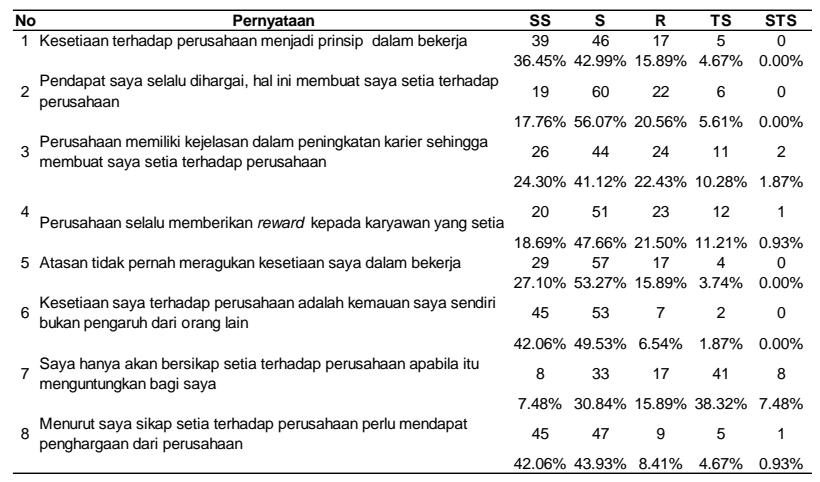

Berdasarkan tabel kesetiaan di atas, didapati bahwa HR Leader setuju bahwa kesetiaan terhadap perusahaan menjadi prinsip dalam bekerja sebesar $42,99 \%$. Setuju bahwa pendapatnya selalu dihargai, hal ini membuat HR Leader setia terhadap perusahaan 56,07\%. Setuju bahwa perusahaan memiliki kejelasan dalam peningkatan karier sehingga membuat saya setia terhadap perusahaan sebesar $4 I, I 2 \%$. Setuju bahwa perusahaan selalu memberikan reward kepada karyawan yang setia sebesar 47,66\%. Atasan tidak pernah meragukan kesetiaan saya dalam bekerja, responden setuju sebesar $53,27 \%$. Kesetiaan saya terhadap perusahaan adalah kemauan saya sendiri bukan pengaruh dari orang lain sebesar $49,53 \%$. Tidak setuju bahwa hanya akan bersikap setia terhadap perusahaan apabila itu menguntungkan bagi HR Leader, sebesar 38,32\%. Setuju bahwa bersikap setia terhadap perusahaan perlu mendapat penghargaan dari perusahaan sebesar $43,93 \%$.

\section{KESIMPULAN DAN SARAN}

Berdasarkan hasil penelitian yang dilakukan terhadap 107 responden $H R$ leader pada komunitas SDM, yaitu SDM Cendekia, Gen HR, Gerakan Nasional Indonesia Kompeten (GNIK), HRBP, Sahabat Kompetensi Indonesa (SKI), dan komunitas SDM lainnya di mana responden tersebar di seluruh wilayah Indonesia, sebagian besar responden adalah laki-laki berjumlah 60 orang $(56,1 \%)$. Sedangkan untuk usia responden yang terbanyak dengan jumlah 44 orang $(41,10 \%)$ adalah generasi milenial yang berusia 36-40 tahun. Lama berkerja sebanyak $43.00 \%$ dengan jumlah 46 orang yaitu antara 6-10 tahun. Data yang telah diperoleh dapat disimpulkan bahwa:
I. Integritas $H R$ leader dalam hal kejujuran masuk dalam kategori tinggi atau sangat baik, hal ini dibutikan dengan indicator tentang mengutamakan perilaku jujur dalam menjalankan pekerjaan sebesar $73,83 \%$ mengisi sangat setuju.

2. Integritas $H R$ leader dalam amanah adalah titipan yang harus diterima, dijalankan, dan dijaga dengan baik. Terbukti dengan presentase terbanyak terdapat pada indikator tentang pekerjaan yang saya lakukan adalah titipan dari Tuhan sebenyak $73,83 \%$ mengisi sangat setuju.

3. Integritas $H R$ leader dalam komitmen untuk berkontribusi pada organisasi cukup tinggi, dengan nilai indikator tertinggi pada kerja efektif merupakan komitmen dalam menjalankan setiap aktivitas kerja sebesar $56,07 \%$ mengisi sangat setuju.

4. Integritas $H R$ leader dalam Kesetiaan cukup tinggi dikarenakan indikator yang menyatakan pendapatnya selalu dihargai, hal ini membuat HR Leader setia terhadap perusahaan $56,07 \%$ mengisi setuju.

Kepemimpinan pada generasi milenial perlu dibangun. Kepemimpinan tersebut berlandaskan integritas dengan nilai kejujuran, amanah, komitmen, dan kesetiaan. Dalam konteks keindonesiaan, membangun pemimpin saat ini, terutama dengan revolusi mental, maka generasi milenial inilah yang menjadi target penting untuk diutamakan.

Nilai-nilai integritas, seperti kejujuran, amanah, komitmen, dan kesetiaan menjadi hal penting untuk dijaga dan ditingkatkan. Saat ini, para HR Leader merasa bahwa nilai-nilai tersebut telah dijalankan dengan baik. Ditambahkan dari hasil kuesioner, para $H R$ Leader ini tidak akan memikirkan kepentingan mereka sendiri. Sebagian besar HR Leader tidak setuju bahwa mereka hanya akan bersikap setia terhadap perusahaan apabila itu menguntungkan bagi diri mereka sendiri.

Menjadi pemimpin yang memiliki integritas tentunya ada beberapa kriteria yang harus dipenuhi di dalam pelaksanaannya, di antaranya adalah seorang pemimpin harus memiliki berkarakter. Karakter merupakan suatu hal mendasar yang harus dimiliki oleh seorang pemimpin di dalam 
dirinya. Karakter tersebut menampilkan apa yang dipikirkan dan apa yang harus dijalankan. Sebagai seorang pemimpin, terutama kepemimpinan di bidang SDM, diharapkan mereka harus memiliki integritas dan berkomitmen untuk menjalankan tindakan tersebut secara nyata, sejalan antara apa yang diucapkan dengan apa yang dilakukan. Dengan integritas: jujur, amanah, komitmen, dan kesetiaan, maka seorang pemimpin tidak akan menabrak rambu-rambu moral, misal melakukan korupsi, kolusi dan nepotisme (KKN) dalam bentuk dan sekecil apapun. Integritas merupakan suatu bagian yang sangat penting dimana harus dimiliki oleh seorang pemimpin, $H R$ Leader, di dalam dirinya, terutama pada generasi milenial saat ini.

\section{UCAPAN TERIMA KASIH}

Kami berterima kasih banyak kepada Jurnal Arterior yang telah memberikan kesempatan artikel ini terbit. Kami juga mengucapkan banyak terimakasih kepada para HR Leader di komunitas SDM Cendekia, HRPB Indonesia, SKI, Gen HR, dll., yang telah berkontribusi pada penelitian ini.

\section{REFERENSI}

Achmad, R. W., Poluakan, M. V., Dikayuana, D., Wibowo, H., \& Raharjo, S. T. (2020). Potret Generasi Milenial Pada Era Revolusi Industri 4.0. Focus : Jurnal Pekerjaan Sosial, 2(2), 187. https://doi.org//0.24| 98/focus.v2i2.2624 |

Agung, I. M., \& Husni, D. (2017). Pengukuran Konsep Amanah dalam Pendekatan Kualitatif dan Kuantitatif. Jurnal Psikologi, 43(3),

194. https://doi.org/10.22 I46/jpsi. I 1233

Aisyah, S. (2019). Menanamkan Nilai Kejujuran Sebagai Revolusi Mental Pada Generasi Penerus Bangsa. Tarbiyah Wa Ta'lim: Jurnal Penelitian Pendidikan Dan Pembelajaran, 6(1), 10I-108. https://doi.org//0.21093/twt.v6i2.2028

Ali, M., Gashti, H., \& Farhoudnia, B. (20I4). THE RELATIONSHIP BETWEEN LEADERSHIP STYLES , EMPLOYEE SATISFACTION International Journal of Human Resource \& Industrial Research I Mohammad. June. Diakses dari http://www.arseam.com/content/volumeI-issue-2-june-20|4
Amirin, T. M. (2007). Kepemimpinan yang amanah. Dinamika Pendidikan, II, I-II. Diakses dari http://eprints.uny.ac.id/id/eprint/4969

Arikunto. (2005). Metode Penelitian Kualitatif. Jakarta: Sagung Seto.

Arisma, Y., Josanti, \& Evimalinda, R. (2019). Nilai - Nilai Integritas Seorang Pemimpin Kristen. Jurnal Teologi Dan Pendidikan Agama Kristen, 4(2), 57-66. https://www.researchgate.net/publication/343205846_ Nilai-

Nilai_Integritas_Seorang_Pemimpin_Kristen?enrichld $=$ rgreq-b2d95ec35d2697d2659159546de66f08-

XXX\&enrichSource=Y292ZXJQYWdIOzMOMzlwNTg 0NjtBUzo5MTcwNDMyMzQ3NDYzNjIAMTU5NTY I MTUIMzYyOA\%3D\%3D\&el=I_x_2\&_esc=

Darmawan, A., \& Putri, M. A. (2016). Pengaruh Gaya Kepemimpinan terhadap Komitmen Organisasi Melalui Kepuasan Kerja Sebagai Variabel Intervening. Akuntabilitas, $9(\mathrm{I}), \mathrm{I}, \mathrm{I8}$. https://doi.org/ I0.15408/akt.v9il.358I

Dwi, Y. P. (20I7). KAJIAN KEPRIBADIAN MORAL PARA TENAGA KERJA SEBAGAI LANDASAN DALAM PENGIMPLEMENTASIAN DUNIA KERJA (Studi Deskriptif Nilai-Nilai Moral Aristoteles pada Karyawan di Beberapa Perusahaan di Jakarta). VOCATIO: Jurnal Ilmiah Ilmu Administrasi Dan Sekretari, I(I), 39-47. http://journal.wima.ac.id/index.php/VOCATIO/article/ view/II67

Halimsetiono, E. (20l4). Peningkatan Komitmen Organisasi untuk Menurunkan Angka Turnover Karyawan Improvement of Organizational Commitment to Lower Employee Turnover. Jurnal Kesehatan Masyarakat Nasional, 8(8), 339-345.

Gea, A. A. (2014). Integritas Personal dan Kepemimpinan Etis. Humaniora, $5(2)$, 950. https://doi.org//0.215I2/humaniora.v5i2.3197

Gilbert, C., De Winne, S., \& Sels, L. (2010). The influence of line managers and HR department on employees' affective commitment DEPARTMENT OF MARKETING AND 
ORGANISATION STUDIES (MO ). https://doi.org//0.1080/09585192.2011.565646

Hadiansyah, A., \& Yanwar, R. P. (20I7). Pengaruh Etos Kerja Terhadap Kinerja Karyawan PT. AE. JURNAL Al-AZHAR INDONESIA SERI HUMANIORA, 3(2), 150. https://doi.org//0.36722/sh.v3i2.204

Hapsari, G. W., \& Masud, F. (2018). Praktik Kepemimpinan Islam ( Studi Fenomenologi Pada Manajer Rumah Sakit Pku Muhammadiyah Temanggung ). Diponegoro Journal of Management, 7(4), I-16. Diaskes dari https://ejournal3.undip.ac.id/index.php/djom/article/vie $\underline{w / 22379}$

Hidayatullah, S., Waris, A., Devianti, R. C., Sari, S. R., Wibowo, I. A., \& Pw, P. M. (2000). Perilaku Generasi Milenial dalam Menggunakan Aplikasi Go-Food. 240-249.

Iqbal, M., \& Prawening, C. (20I8). REFLEKSI KEBENARAN: PRINSIP KEJUJURAN SEBAGAI KOMUNIKASI SPIRITUAL ANAK DI ERA DIGITAL. Al-Balagh: Jurnal Dakwah Dan Komunikasi, 3(2), 175-192. http://www.elsevier.com/locate/scp

Jha, N., Sareen, P., \& Potnuru, R. K. G. (2019). Employee engagement for millennials: considering technology as an enabler. Development and Learning in Organizations, 33(I), 9-II. https://doi.org//0.II08/DLO-05-20I80057

Kasidi. (2016). HUBUNGAN ANTARA KOMITMEN KEPEMIMPINAN DAN BUDAYA ORGANISASI DENGAN KINERJA GURU DI SMP NEGERI SEKECAMATAN PUTRI HIJAU.

10 https://ejournal.unib.ac.id/index.php/manajerpendidika n/article/view// 270.

Keselman, D. (2012). Ethical leadership. Holistic Nursing Practice, 26(5), 259-26I. https://doi.org/10.1097/HNP.0b013e318263f2da

Lalo, K. (2018). Menciptakan Generasi Milenial Berkarakter dengan Pendidikan Karakter guna Menyongsong Era Globalisasi. Jurnal IImu Kepolisian, I2(2), 68--75. Diakses dari
http://www.jurnalptik.id/index.php/JIK/article/view/23

Lemeshow, S.. Hosmer Jr., D. W., Klar, J., \& Lwanga, S. K. (1990). Adequacy of Sample Size in Health Studies. John Wiley \& Sons. England.

Maulana, E., Nurhasanah, N., \& Senjiati, I. H. (2018). Analisis Aspek Kejujuran dalam Akhlak Pelayanan Penggantian Oli Oleh Karyawan ( Studi Kasus Pada Salah Satu Bengkel Honda di Kota Bandung ) Aspect Analysis Honesty in the morals of Oil Replacement services by Employees ( Case Study On One Of Honda Worksho. Hukum Ekonomi Syariah, 4(2), 85I-856. Diakses dari http://karyailmiah.unisba.ac.id/index.php/hukum_ekono mi_syariah/article/view/108/8/pdf

Mondiani, T. (20I2). Pengaruh Kepemimpinan Transformasional Dan Kompensasi Terhadap Kinerja Karyawan Pt . Pln ( Persero ) Upj Semarang. Jurnal Administrasi Bisnis Volume, I, 46-54. https://doi.org/10.14710/jab.vlil.4317.

Muhasim. (2017). BUDAYA KEJUJURAN DALAM MENGHADAPI PERUBAHAN ZAMAN__ _. Jurnal Studi Keislaman Dan IImu Pendidikan, 5(I), 174-195. DOI: https://doi.org//0.36088/palapa.v5il.78

Mulyati, R., Himam, F., Riyono, B., \& Suhariadi, F. (20/9). Model Work Engagement Angkatan Kerja Generasi Millennial dengan Meaningful Work sebagai Mediator. Gadjah Mada Journal of Psychology (GamajoP), 5(I), 34. https://doi.org/I0.22146/gamajop.47964

Noviandani, M. I., \& Septiarini, D. F. (20I7). NILAI - NILAI AMANAH SEBAGAI STRATEGI FUNGSIONAL PADA RUMAH MAKAN WONG SOLO CABANG GRESIK. Journal of Chemical Information and Modeling, 53(9), 21-25. diakses dari http://www.elsevier.com/locate/scp

Peramesti, N. P. D. Y., \& Kusmana, D. (20I8). Kepemimpinan Ideal Pada Era Generasi Milenial. TRANSFORMASI: Jurnal Manajemen Pemerintahan, 73-84. https://doi.org//0.3370I/jt.v10il.413

Perdana, S. dalam S. \&. (20|6). Antecedents variable of 
employee loyalty. Jurnal Manajemen Dan Kewirausahaan,

I8(2), II3. https://doi.org//0.9744/jmk.18.2.III

DOI: https://doi.org/|0.9744/jmk.18.2.1।I-1/8

Redjeki, D. P. S., \& Herdiansyah, J. (20I3). Memahami Sebuah Konsep Integritas. Jurnal Pelopor Pendidikan STIE Semarang, 5(3), I-14.

Robbins dan Judge. (2015). Pengertian gaya kepemimpinan. Journal of Chemical Information and Modeling, 53(9), 1689-1699.

Sugiyono. (2012). Metode Penelitian Kuantitatif Kualitatif dan R \& D. Bandung: Alfabeta

Sinulingga, S. P. (2016). Teori Pendidikan Moral Menurut Emile Durkheim Relevansinya Bagi Pendidikan Moral Anak Di Indonesia. Jurnal Filsafat, 26(2), 214--247. https://doi.org/https://doi.org//0.22| 146/jf. 12784

Sultraini, R., Bogar, W., \& Tangkau, C. H. S. (2019). Perilaku Kepemimpinan Organisasi Dalam Pengambilan Keputusan Pada Badan Kepegawaian Pendidikan Dan Pelatihan Kabupaten Minahasa Utara. Jurnal Mirai Management, 4(I), 73-86. diakses dari https://www.journal.stieamkop.ac.id/index.php/mirai/ar ticle/view/437

Suryadi, B., Umar, J., Nisa, Y. F., \& Sumiati, N. T. (2016). Pengembangan Instrumen Integritas Pribadi. 1-12.

Wahono, M. (20I8). Pendidikan Karakter: Satu Kebutuhan Bagi Mahasiwa Di Era Milenial. Integralistik, 29(2), I-8. https://doi.org/https://doi.org// 0.15294/integralistik.v2 $9 \mathrm{i} 2.16696$

Wahyudin, A. H. (2016). AN-NIDHOM Jurnal Manajemen Pendidikan Islam) INTEGRITAS MORAL PEMIMPIN: ANTARA CITA DAN FAKTA Ade Herlan Wahyudin. I(I). diakses dari http://jurnal.uinbanten.ac.id/index.php/annidhom/articl e/view/l02

Widyarini, I., Yuniarti, K. W., Nugraha, L. A., Psikologi, J., \& Brawijaya, U. (2019). Kerangka Konseptual Integritas : Studi Eksplorasi pada Guru-guru Sekolah Dasar di Yogyakarta. MEDIAPSI, 5(I), 16-29. https://doi.org/https://doi.org//0.21776/ub.mps.2019.0 05.01 .2

Wijaya, H. (20I5). Keunggulan Integritas Generasi Muda Dalam Mewujudkan. Https:///Www.Researchgate.Net/Publication/2836664535 , November. https://doi.org/I0.I3|40/RG.2.I.4264.9048

Wisesa, A. (2002). Integritas Moral Dalam Konteks Pengambilan Keputusan Etis. Journal of Technology Management, https://journal.sbm.itb.ac.id/index.php/mantek/article/vi ew/I33//24

Yustina, A. I. (2017). Effects of Ethical Leadership on Employee Well-Being: 32(2), | $21-137$.

Zahra, N. (20I5). Pengaruh Gaya Kepemimpinan Terhadap Komitmen Organisasi Melalui Aspek Kepuasan Kerja Karyawan dan Kepercayaan Pada Sektor Perbankan. Jurnal Manajemen Dan Pemasaran Jasa, 8(I), 145-162. https://doi.org/http://dx.doi.org// 0.25I 05/jmpj.v8il. 14 06 